\title{
Sustainability Risk Management of Firms
}

Please cite this article as:

Brătianu, C., 2020. Sustainability risk management of firms. Amfiteatru Economic, 22 (55), pp. 635-637.

\section{DOI: $10.24818 / \mathrm{EA} / 2020 / 55 / 635$}

The COVID-19 pandemic appeared unexpectedly as a black swan phenomenon that demonstrates the powerful impact of the highly improbable. Starting as an epidemic in December 2019 in Wuhan, Hubei Province of China, the COVID-19 disease spread fast with an incredible acceleration due to its high power progression rate. The World Health Organization (WHO) declared the COVID-19 pandemic on $12^{\text {th }}$ March 2020, when there were confirmed more than 125,000 cases from 118 countries and regions all over the world. The health systems crisis generated other crises in the economy, business, education, culture, sports, and social life. All of these phenomena show the paramount importance of understanding the risk and its difficult management task. They confirm the inspiration and vision of the editors of this journal for defining such a topic focusing on sustainability risk management of the firms when nobody could anticipate such an economic earthquake.

Risk is organically associated with uncertainty. The higher the uncertainty level, the higher the potential risk when making decisions. If managers make their decisions considering certain events and well-defined principles, then there is no risk in choosing the best alternative of action. But that is an ideal situation when managers know everything they need to know, and the future is considered as an extension of the present time. In reality, the future is not a linear extension of the present, as many managers considered it at the beginning of strategic planning but a series of uncertain events as a result of the absence of knowledge. Risk management aims at analyzing decision-making from this perspective of uncertainty and finding adequate solutions with respect to a set of criteria and a spectrum of identifiable alternatives.

We have to make a distinction between subjective risks and objective risks. The subjective risks refer to the perception of risks that is a subjective phenomenon and different for different people. For instance, a new and complex phenomenon that is not fully understood may be interpreted as an opportunity by an entrepreneur or as a threat by a conservative manager. The objective risks are based on using data and probability distributions to identify and evaluate the possible consequences of producing some events. The potential risk of a certain event can be computed by multiplying the probability of realizing that event and the possible economic consequences of its realization. Even if some events are very improbable, if their consequences will produce a high level of human, material, and economic damage, the risk is very high. Here we consider earthquakes, floods, hurricanes, epidemics, and other natural and social disasters.

Sustainability risk management focuses on those risks that lead to erosion or even losing chances for a sustainable business. Sustainability is very important for any business today because of the increasing global competition and economic turbulence. The business philosophy based on profit maximization has been changed in the last decades with the philosophy of competitive advantage and sustainable business. Sustainability is designed in 
a long-run perspective, and it is based on the synergy of the triple factors, i.e., economic, social, and natural environment. Since each of these factors is associated with uncertainty, it results that sustainability risk management is a complex construct with a powerful impact on the managerial strategic thinking and decision-making. The papers selected for the present issues investigate different aspects of this construct, showing its theoretical and practical implications for economics and the business environment.

The impact of knowledge risk on sustainability of firms. This paper analyzes the knowledge risks and their impact on business performance in a long-term perspective. In the knowledge economy, knowledge is a strategic resource, and any vulnerability of knowledge management leads to a potential knowledge risk. The paper is focusing on the risk associated with knowledge loss, which becomes a dominant phenomenon in aging societies, as we witness in all the European countries and in the United States of America.

Risk analysis of a hedge fund oriented on sustainable and responsible investments for emerging markets. The paper addresses the economic problems of emerging markets, characterized by low liquidity and limited diversification possibilities through alternative investments. The paper shows how, starting from a solid analysis of the sustainable and responsible investment, it is feasible to develop a natural and flexible integration of the sustainability principles in active investment strategies for the emerging capital markets.

Non-financial reporting and reputational risk in the Romanian financial sector. The paper focuses on the reputation of a firm that is an important component of the intellectual capital and on the risk associated with it. The paper investigates the ways in which the banking institutions in Romania treat the reputational risk management and how the non-financial reporting contributes to this potential risk.

Environmental, social and governance risks - new challenges for the banking business sustainability. The paper investigates the banking business in Romania from the environmental, social, and governance risk perspective. The research is focused on the quantitative dimension of this problem, and the authors use statistical processing models with the support of the specialized software Stata.

Risk management of companies included in the Euro STOXX Sustainability Index. An investors' perception. The paper analyzes the risk level of investing in the companies included in the STOXX Europe 600, which belong to the Eurozone. By using data extracted from the Bloomberg Professional platform for the period 2010-2020, and considering consolidated risk measurement methodologies, the authors reveal that the companies included in the Euro STOXX Sustainable Index have a lower level of risk than the other companies contained only in the STOXX 600 index.

Risk management implementation for sustainable development of Romanian SMEs: A fuzzy approach. The paper examines the determinants of the SMEs behavior in implementing risk management systems. Data is collected from a sample of SMEs and is processed by using fuzzy mathematical models. Findings show that the attitude toward risk is influenced by the business lifespan and awareness of the importance of risk management.

Diversity, social inclusion, and human development as fundamentals of financial performance and risk mitigation. The paper deals with the human capital development and its influence on financial performance and risk mitigation. The quantitative research is based on econometric models and data extracted from the Thomson Reuters Eikon (2020) database for 1722 companies having their headquarters in Europe. Findings show the risks related to the sustainability of financial performance and the ways of mitigating their consequences.

Business model innovation through the use of digital technologies: managing risks and creating sustainability. It is known that innovation is related to risk, and thus 
promoting innovative strategies aiming to achieve sustainability requires measures to lower the risk level. The paper is focusing on the entrepreneurial behavior of 92 technology-based companies from the European business market and performs quantitative research in order to reveal how managers can develop and implement innovation strategies while avoiding or diminishing the predictable risks. Also, the paper presents a comparative analysis between Eastern and Western European companies concerning risk perception and risk management.

Guaranteed crowdlending loans: A tool for entrepreneurial finance ecosystem sustainability. Crowdlending is a disruptive financial tool that responds especially to the SMEs requests for satisfying their capital needs. However, the new financial mechanism involves a high level of risk. The paper assesses 196 guaranteed loans from the pioneer platform in Spain MytripleA that offers that type of loans, by using a PLS-SEM model of investigation.

The internationalization of SMEs in Central Europe and its impact on their methods of risk management. The paper analyzes the internalization process of SMEs in Central Europe and its impact on risk perception and risk management. Data is collected from V4 countries (i.e., Czech Republic, Hungary, Slovenia, and Poland). The sample contains 1781 valid questionnaires from SMEs. Findings show that companies that are present on the international market are more focused on developing their risk management systems.

Public listing and corporate social responsibility from a sustainability risk management perspective. The paper investigates how the process of public listing of companies in China impacts on their CSR performance. The research is focused on a sample of Chinese IPO firms for the years 2012-2016, and it is using a multiple regression model. Findings show that there is a significant and sustained increase in CSR performance after performing IPO.

Although each paper is investigating a specific aspect of sustainability risk management, together, they aggregate a comprehensive image of the topic, showing its complexity and impact on the business performance in such a dynamic and unpredictable business environment.

\section{Associate Editor Constantin Brătianu}

